\title{
Assessment of Drug Usage Pattern during Pregnancy at a Tertiary Care Teaching Hospital
}

\author{
Bency Mary Varghese, Vanaja K, Reshma Banu
}

\section{Bency Mary Varghese, Vanaja K, Reshma Banu}

\begin{abstract}
'Department of Pharmacy Practice, Visveswarapura Institute of Pharmaceutical Sciences, $24^{\text {th }}$ Cross, $25^{\text {th }}$ Main, $B D A$ complex, BSK $2^{\text {nd }}$ stage, Bangalore 560070
\end{abstract}

\section{Correspondence}

Dr. Vanaja K,

Visveswarapura Institute of Pharmaceutical Sciences, BSK II stage, BDA complex, Bangalore 560070

Email: vanaja.sateesh@gmail.com

\section{Other Authors}

Reshma Banu: reshmaansar12@hotmail. com

Bency Mary Varghese: benzee09@gmail. com

\section{History}

- Submission Date: 03-09-15;

- Review completed: 18-06-16;

- Accepted Date: 22-06-16.

DOI : 10.5530/ijmedph.2016.3.7

Article Available online

http://www.ijmedph.org/v6/i3

\section{Copyright}

(C) 2016 Phcog.Net. This is an open-access article distributed under the terms of the Creative Commons Attribution 4.0 International license.

\begin{abstract}
Objectives: To assess the usage of drugs during pregnancy in the OBG Department at a tertiary care teaching and research hospital in Bangalore city, India.

Materials and Methods: Data was retrieved from participant's ( $n=250$ ) case sheets of OBG department, on daily basis during a period of 7 months. Data was collected during their visit to the hospital and admission for safe confinement, which included demographic details, list of drugs taken, categorization of drugs based on USFDA, ATC and class of drugs were recorded along with the precautions that has to followed while taking these drugs.

Results: Mean age was found to be $24.51 \pm 3.81$ years with $52 \%$ of participants having school level education, $91.21 \%$ were housewives, $32.4 \%$ had medical conditions, $76 \%$ of them practiced self-medication with $77.2 \%$ using OTC drugs, $1.2 \%$ of the study participants had diabetes mellitus before pregnancy and $4 \%$ developed gestational diabetes. Classification based on USFDA categorization as well as the Anatomical and Taxonomical Classification showed that majority of drugs prescribed in our study belonged to the USFDA Category B which are safe to be prescribed during pregnancy, such as anti-infectives $(70.4 \%)$ followed by anti-diabetics $(27.5 \%)$ and anti-anaemics $(26.3 \%)$. Drugs belonging to the category $X$ which are supposed to be contraindicated during pregnancy were not prescribed.

Conclusion: Knowledge about consumption of drugs during pregnancy and its effect on the foetus is important. Hence, a pharmacist can play an important role in reducing the ill-effects of drugs by educating the women on self-medication and the use of drugs during pregnancy. Keywords: ATC classification, Bangalore city, Foetal health, Medication use, USFDA categorization.
\end{abstract}

\section{INTRODUCTION}

Pregnancy is a special physiological condition where drug treatment presents a special concern because netics of medications used and certain medications could cause harm to the foetus due to the potential teratogenic effects of the drug and the physiological adjustments in the mother, in response to pregnancy. ${ }^{1,2}$ Most of the pregnant women need permanent drug treatment due to their chronic diseases such as epilepsy, diabetes mellitus, bronchial asthma, hypertension, thyroid disorders, migraine, and severe depression. ${ }^{3}$ There are major concerns as a permanent harm could occur to the baby whenever any drug is administered to pregnant women. Maternal medications can also increase the incidence of abortion, foetal death, premature/delayed labour or create perinatal problems. Pronounced and progressive physiological changes during pregnancy affects drug disposition, hence prescribing medications for a pregnant woman requires a lot of skill and restraint, during which possible benefit by the administered drug has to be weighed against harm to both mother and the baby due to untreated disease. ${ }^{4}$ The benefits of medicine use during pregnancy are not restricted physiology of pregnancy affects the pharmacoki- to the recovery of maternal health but also result in some advantages for the baby as well, because the maternal well-being is important for the optimal development of the foetus. ${ }^{3}$

Many studies have been conducted in different parts of the world to assess the drug usage pattern during pregnancy. A study conducted to describe the pattern of drug use among Chinese women during the first trimester and to examine the impact of maternal diseases on the choice of drugs especially with the Chinese traditional patent medications (CTPM) revealed that maternal chronic diseases were not associated with the use of CTPM. ${ }^{5}$ Another study to assess the pattern of drug use amongst antenatal women in Nigeria showed that drug use in pregnancy was characterised by a pattern of low consumption except folic acid and native herbs. ${ }^{6}$ A study on drug utilization pattern in North India revealed that self-medication and herbal drugs use was more in graduates than in undergraduates, as well as it was more in the higher socio-economic group than when compared to the lower socio-economic group. ${ }^{1}$

Attitudes and practices towards prescribing in pregnancy has greatly changed following the thalidomide disaster about 30 years ago.
Cite this article : Varghese BM, Vanaja K, Banu R. Assessment of Drug Usage Pattern during Pregnancy at a Tertiary

Care Teaching Hospital. J. Med. Public Health, 2016; 6(3):130-5. 
At present it is recommended that drugs should be avoided as much as possible during pregnancy.

The question of prescription quality and drug use by practitioners and women has not been adequately clarified or regularly reported. In addition, the pattern of drug prescribing in pregnancy may change rapidly as a consequence of changes which occur in the pharmaceutical market. Patients vary substantially in regard to their knowledge about safe medication use during pregnancy. Although many authorities have argued for restraint in medication prescribing during pregnancy, drug usage still continues.

Study of drug usage pattern in a South Indian city like Bangalore has been limited, hence the objective of the study was to assess the usage of drugs during pregnancy at a tertiary care teaching hospital. The present study gives a collective information of drug usage, its safety based on USFDA guidelines, evaluating the pattern of prescribing drugs, which would add to database about safe medication in pregnancy.

\section{METHODOLOGY}

A prospective observational study was conducted at the department of OBG in a 1000 bedded tertiary care teaching hospital, Bangalore South, India for a period of 7 months. The study was carried out under the declaration of Helsinki after obtaining the ethical clearance from the Institutional Human Ethical Committee Board.

A total of 250 participants attending the antenatal clinic of the institution were included in the study and informed consent was obtained prior to the study. Using the online sample size calculator, ${ }^{7}$ a sample size of 246 was calculated with $95 \%$ confidence interval (CI) and the desired width of CI was 5 and the standard deviation of the variable was 20. As per the observation by the treating gynaecologist, the average of number of pregnant woment visiting the antenatal clinic was 20 per day. Sample consisted of all pregnant women attending the ante-natal clinic of the institution during the study period who met the inclusion and exclusion criteria.

Both in-patient and out-patient pregnant women including those having medical history for hypertension, diabetes mellitus, asthma were included. Pregnant women on anti-retroviral therapy (ART) were excluded. A structured questionnaire was designed and the pregnant women were interviewed in the local language to collect information which included

a) Basic socio-demographic details such as age, education, occupation, place of residence, child bearing trimester, parity, timing of 1st prenatal visit, abortion history, habits, use of herbal products, maternal chronic diseases, medications taken, medical condition before pregnancy.

b) Information about drug use including the generic and brand name of the drug, dose, dosage frequency and route of administration.

c) Information regarding their knowledge on the safety of use of medications during pregnancy was also obtained along with their practice of purchasing over the counter (OTC) drugs and self-medication during pregnancy.

From the data collected the drugs were further classified based on USFDA categorization (category A, B, C, D and X), anatomical classification and the different class of drugs. During the study period 174 participants of the total study population $(n=250)$ were further observed for drug effects if any for a week post-partum.

\section{RESULTS}

The present study involved a total of 250 pregnant women which included participants of all three trimesters, passing the inclusion criteria and gave informed consent to participate during their visit to the hospital and their safe confinement. All the participants received one or more drugs including vitamins and minerals. From the 250 participating women, data about their previous medical conditions, chronic illnesses and history of the medications taken for the same was collected.

Among the 250 participating women, 17 of them belonged to the first trimester, 19 of the second trimester whereas majority of them i.e. 214 were in the third trimester of pregnancy.

The overall mean age of the participants was found to be $24.51 \pm 3.81$ years ranging from $<20$ years to $>35$ years. $92.8 \%$ of the participating women were from urban regions among which majority of the women were housewives with school level education. $39.6 \%$ of the participating women had their first prenatal visit between 12-25 weeks with $44 \%$ being primigravida (Table 1).

\section{Table I: Demographic details and pregnancy status of the study participants}

\begin{tabular}{|c|c|}
\hline VARIABLES & N (\%) \\
\hline \multicolumn{2}{|l|}{ Age (years) } \\
\hline$<20$ & $13(5.2)$ \\
\hline $20-25$ & $158(63.2)$ \\
\hline $26-30$ & $61(24.4)$ \\
\hline $31-35$ & $14(5.6)$ \\
\hline$>35$ & $4(1.6)$ \\
\hline \multicolumn{2}{|l|}{ Occupation } \\
\hline Housewife & $228(91.2)$ \\
\hline Lecturer & $9(3.6)$ \\
\hline Others & $13(5.2)$ \\
\hline \multicolumn{2}{|l|}{ Education } \\
\hline No formal education & $104(41.6)$ \\
\hline School level & $130(52)$ \\
\hline Degree level & $16(6.4)$ \\
\hline \multicolumn{2}{|l|}{ Place of stay } \\
\hline Urban & $232(92.8)$ \\
\hline Rural & $18(7.2)$ \\
\hline \multicolumn{2}{|l|}{$1^{\text {st }}$ Prenatal visit } \\
\hline$<12$ weeks & $89(35.6)$ \\
\hline weeks & $99(39.6)$ \\
\hline$>25$ weeks & $62(24.8)$ \\
\hline \multicolumn{2}{|l|}{ Gravida } \\
\hline 1 & $110(44)$ \\
\hline 2 & $84(33.6)$ \\
\hline 3 & $40(16)$ \\
\hline 4 & $13(5.2)$ \\
\hline 5 & $1(0.4)$ \\
\hline 6 & $2(0.8)$ \\
\hline \multicolumn{2}{|l|}{ Abortion history } \\
\hline Yes & $58(23.2)$ \\
\hline No & $192(76.8)$ \\
\hline \multicolumn{2}{|l|}{ Trimester } \\
\hline First & $17(6.8)$ \\
\hline Second & $19(7.6)$ \\
\hline Third & $214(85.6)$ \\
\hline \multicolumn{2}{|l|}{ Appetite } \\
\hline Good & $147(58.8)$ \\
\hline Moderate & $100(40)$ \\
\hline Poor & $3(1.2)$ \\
\hline
\end{tabular}


Table 2: Details regarding illness, medication and knowledge of effects of drugs during pregnancy

\begin{tabular}{cccc}
\hline SI. No. & Variables & YES & NO \\
& Presence of Illness & N (\%) \\
\hline 1 & Pregnancy with medical condition & & \\
2 & Medical condition before pregnancy & $81(32.4)$ & $169(67.6)$ \\
3 & Chronic disease during pregnancy & $27(1.8)$ & $223(89.2)$ \\
& Medication Use & $55(22)$ & $195(76)$ \\
1 & Drugs taken during medical conditions & $60(24)$ & $190(76)$ \\
2 & Drugs taken during chronic condition & $52(20.8)$ & $198(79.2)$ \\
3 & Exposure of drugs with vitamins and minerals & $54(21.6)$ & $196(78.4)$ \\
4 & Exposure of drugs without vitamins and minerals & $29(11.6)$ & $221(88.4)$ \\
5 & Folic acid and calcium taken & $229(91.6)$ & $21(8.4)$ \\
6 & Tetanus injection taken & $218(87.2)$ & $32(12.8)$ \\
7 & Herbal products taken & $16(6.4)$ & $234(93.6)$ \\
8 & Over the counter drugs used & $193(77.2)$ & $57(22.8)$ \\
9 & Self-medication & $190(76)$ & $60(24)$ \\
& Knowledge about harmful effects of drugs on baby & $122(48.8)$ & $128(51.2)$ \\
\hline
\end{tabular}

Table 3: Chronic illness observed in the study participants during the three trimesters

\begin{tabular}{ccccc} 
& \multicolumn{3}{c}{$\begin{array}{c}\text { Before pregnancy } \\
\mathbf{n}=\mathbf{2 5 0}\end{array}$} & $\begin{array}{c}\text { During pregnancy } \\
\mathbf{n}=250\end{array}$ \\
\cline { 2 - 5 } Chronic Illness & & Trimester 1 & Trimester 2 \\
$(\mathbf{n}=17)$ & $\mathbf{N}(\%)$ & $\mathbf{N}(\%)$ & $\begin{array}{c}\text { Trimester 3 } \\
(\mathbf{n}=214)\end{array}$ \\
\cline { 2 - 5 } & $\mathbf{N}(\%)$ & $3(17.6)$ & $9(47.3)$ & $\mathbf{N}(\%)$ \\
\hline Hypertension & - & $1(5.8)$ & $1(5.2)$ & 0 \\
BED $^{*}$ & $1(0.4)$ & $5(29.4)$ & $3(15.7)$ & $1(0.4)$ \\
Diabetes Mellitus & $3(1.2)$ & $1(5.8)$ & $1(5.2)$ & $3(1.4)$ \\
UTI & - & $1(5.8)$ & 0 & 0 \\
UTI + Hypertension & - & $2(11.7)$ & $2(5.7)$ & $7(3.2)$ \\
Anaemia & $1(0.4)$ & $1(5.8)$ & 0 & $2(0.9)$ \\
Hypothyroidism & $7(2.8)$ & $4(18.1)$ & $4(20.9)$ & $181(84.8)$ \\
Normal & $234(93.6)$ & & & 0 \\
\hline
\end{tabular}

${ }^{*} \mathrm{BED}$-Bipolar Effective Disorder.

†UTI-Urinary Tract Infection.

Table 4: USFDA categorization of drugs taken during different trimesters

\begin{tabular}{|c|c|c|c|c|}
\hline \multirow[b]{3}{*}{ Trimester } & \multicolumn{3}{|c|}{ USFDA CLASSIFICATION } & \multirow[b]{2}{*}{ D } \\
\hline & $A$ & B & C & \\
\hline & $\mathrm{N}(\%)$ & $\mathrm{N}(\%)$ & $\mathrm{N}(\%)$ & $\mathrm{N}(\%)$ \\
\hline $1(n=17)$ & $9(39.1)$ & $10(28.5)$ & $3(23)$ & $1(14.2)$ \\
\hline $2(n=14)$ & $1(4.3)$ & $5(14.2)$ & $2(15.3)$ & $1(14.2)$ \\
\hline $3(n=214)$ & $13(56.5)$ & $20(57.1)$ & $8(61.5)$ & $5(71.4)$ \\
\hline
\end{tabular}

$\mathrm{n}=$ No. of participants in the respective trimesters.

$\mathrm{N}(\%)=$ No. of drugs in the respective USFDA category (out of total participants in each trimester).

USFDA: United States Food and Drug Administration.

Category A: safest drugs, Category B: failed to demonstrate a risk to the foetus,

Category C: can be used if benefits overweigh the risks, Category D: implies risk. 


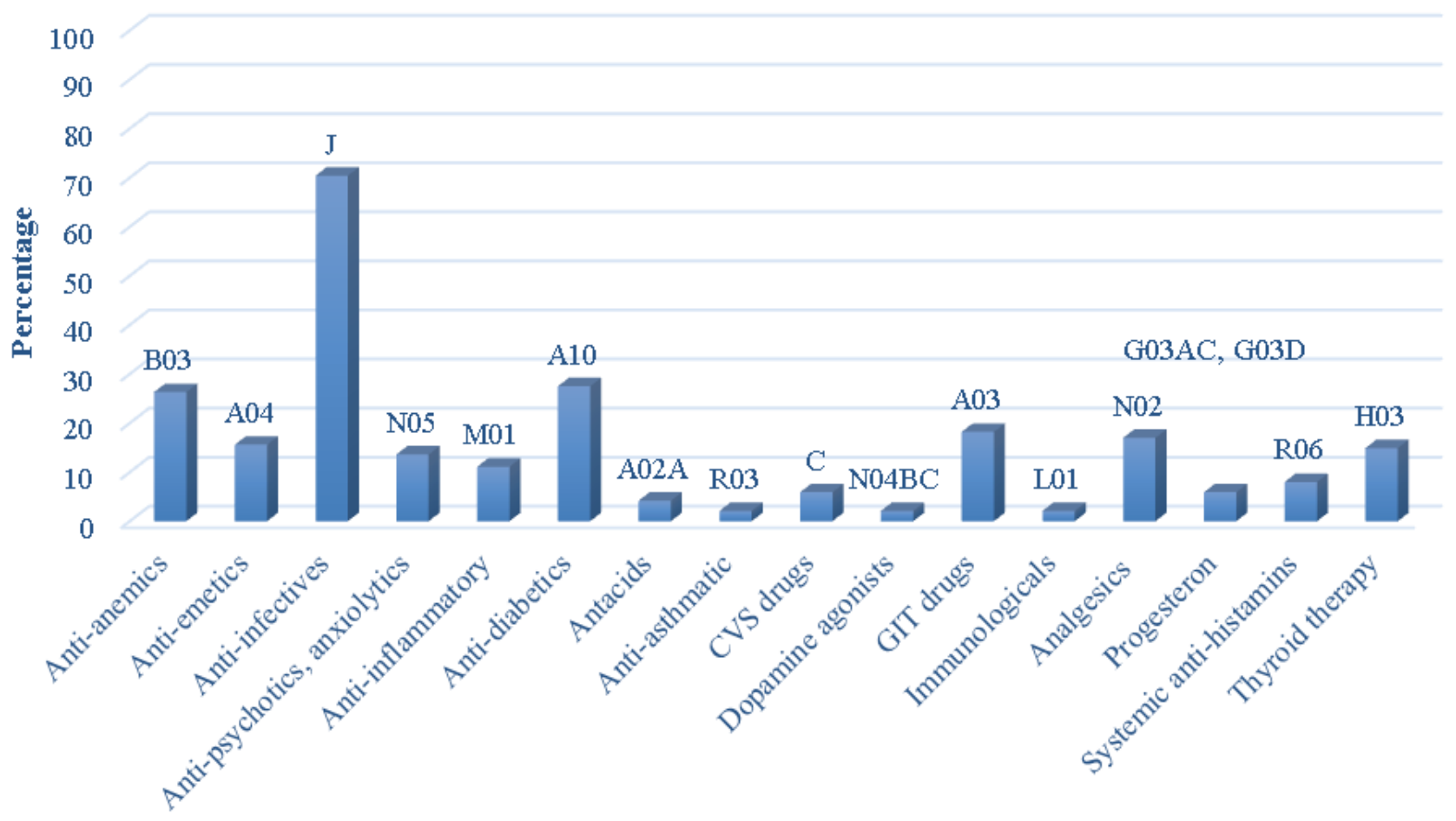

ATC Classification

Figure 1: Anatomical and Taxonomical classification of drugs used by the study participants.

Note: The ATC codes for the respective classes of drugs have been indicated above each bar graph.

Data from the questionnaire (Table 2) revealed that $32.4 \%$ of the participating women had medical conditions (breathlessness, cough, chicken pox, cold, emesis, enteric fever, fever) during pregnancy and $10.2 \%$ had medical conditions before pregnancy. $22 \%$ of women suffered from chronic illnesses (hypertension, bipolar effective disorder, anaemia, urinary tract infection, hypothyroidism, and diabetes mellitus) during pregnancy and among them $20.8 \%$ were treated for the same. Participants were exposed to drugs including vitamins and minerals (21.6\%) whereas majority of them received folic acid and calcium (91.6\%). TT (tetanus) was administered to $87.2 \%$; herbal products were not used by $93.6 \%$ of the participants; OTC drugs were used by $77.2 \%$ with selfmedication being practiced by $76 \%$ of them. Majority of the participating women $(51.2 \%)$ did not possess sufficient knowledge about the harmful effects of drugs on the foetus.

During the antenatal check-up, the lab data such as BP (Blood Pressure), Hb (Haemoglobin), RBS (Random Blood Sugar) and TSH (Thyroid Stimulating Hormone) levels were measured. As shown in Table 3, only $18.1 \%\left(1^{\text {st }}\right.$ trimester $), 20.9 \%\left(2^{\text {nd }}\right.$ trimester $)$ and $84.8 \%$ ( $3^{\text {rd }}$ trimester) were found to be normal with no chronic illness whereas the remaining participants developed an illness which necessitated the use of drugs. It was observed that during $1^{\text {st }}$ trimester $29.4 \%$ developed gestational diabetes, $17.6 \%$ developed eclampsia (hypertension), 11.7\% developed anaemia and few participants (5.8\%) had BED (Bipolar Effective Disorder), UTI (Urinary Tract Infection), UTI with hypothyroidism and hypothyroidism. Whereas during the $2^{\text {nd }}$ trimester, higher number of study participants had developed eclampsia followed by gestational diabetes (15.7\%) and anaemia (5.7\%) and few developed BED and UTI (5.2\%). In the $3^{\text {rd }}$ trimester participants who developed eclampsia were found to be the highest $(9.3 \%)$, followed by anaemia (3.2\%) with less number of participants having gestational diabetes (0.4\%), UTI (1.4\%) and hypothyroidism (0.9\%).

Drugs administered during all three trimesters were classified based on the USFDA categorisation. The most commonly prescribed were Category B drugs which included diazepines, antibiotics, beta blockers and anti-fungals; followed by the category A drugs such as vitamins and minerals, thyroid hormones and insulin preparations. Drugs belonging to Category $\mathrm{C}$ drugs were also used, which were calcium antagonists, alpha adrenergic agonists and vasodilators. Category D drugs such as benzodiazepines were the least prescribed. All the categories of drugs were prescribed maximum during the third trimester. The anatomical classification of drugs revealed that anti-infectives were the most commonly prescribed drugs (55.5\%). The second highest drugs prescribed were anti-diabetics $(27.5 \%)$. The remaining prescriptions referred to a variety of drug classes which were taken for a broad spectrum of indications as observed in Figure 1. The respective ATC codes for the different classes of drugs have been shown as data labels above each graph bar.

Further to this, drug usage pattern post-partum data was recorded for 174 patients. The post-delivery data revealed that out of 174 new born babies, $94.3 \%$ of them were healthy and $2.9 \%$ were still born or had conditions such as hyperbilirubinemia, tachypnea and were underweight. Among these there was only 1 participant who was prescribed with category D drug (gentamycin) during the first trimester, 2 participants received category $\mathrm{D}$ (clonazepam) and $\mathrm{X}$ (methyldopa) drugs during their second and third trimesters respectively.

\section{DISCUSSION}

Maternal drug use during pregnancy could cause a teratogenic risk for the foetus, however it is unrealistic and could be dangerous if the 
recommendation of drug usage is avoided during pregnancy. Total avoidance of pharmacological treatment in pregnancy is difficult because some women enter pregnancy with medical conditions which requires a continued treatment such as in case of hypertension, diabetes mellitus, epilepsy, asthma, and hypothyroidism. Hence drugs are important and essential for maintaining good health of the pregnant women and the foetus. Many women take drugs during pregnancy, however, the extent of the drug prescription and the type of drugs prescribed are very difficult to ascertain. ${ }^{9}$

To collect the complete information of drug prescriptions in pregnant women, this prospective study was conducted in a 1000 bedded tertiary care teaching and research hospital. All the 250 participants received one or more drugs (including vitamins and minerals).

Analysis of age distribution revealed that the pregnancy was highest in the age group of 20-25 years and the mean age was $24.51 \pm 3.8$ years. The educational status of the study population reported in other countries was higher in comparison to our study in which majority of the participants (52\%) had only school level of education. Nearly $93 \%$ were from urban regions with maximum of them being housewives (91.2\%). The order of pregnancy revealed that majority of the participants in this study were primigravida which is similar to studies reported by Adhikari et al and Sharma et al conducted in Central and Northern parts of India respectively. ${ }^{10,1}$

The timing of the first prenatal visit showed that most of the women attended clinics during 12-25 weeks which was similar to a study reported in China by Zhu et al. ${ }^{5}$ It was seen that maximum number of participants $(76.8 \%)$ did not have an abortion history similar to the study by Zhu et al. ${ }^{5}$

Awareness about the harmful effects of drugs on the foetus was known and unknown equally among the study participants. Self-medication was highly practiced (76\%) which correlated with the high usage of OTC medications (77.2\%) such as analgesics and anti pyretics which is similar to the study reported by the C.G.D.U.P group. ${ }^{10}$ Iron and vitamin supplementation were the most commonly used drugs similar to studies reported by a Malm $\mathrm{H}$ et al and Sharma et al. ${ }^{1,12}$ Half of pregnant women were exposed to iron in half of the countries investigated whereas $50 \%$ of women were prescribed vitamins in $1 / 3^{\text {rd }}$ of the country. ${ }^{11}$

Use of herbal drugs was reported to be low among our study participants which was not similar to the studies reported by Maats FH et al. ${ }^{13} \mathrm{Herbal}$ preparations are classified as dietary supplements by FDA and are not regulated as conventional drugs. ${ }^{1}$

Apart from the drug therapy the chronic drug prescription was used for long standing medical conditions in which BED (Bipolar Effective Disorder), DM (Diabetes Mellitus), anaemia and hypothyroidism were observed in the participants before pregnancy. The majority of the prescriptions were for hypertension, with the highest number being during the third trimester, followed by diabetes mellitus, anaemia and hypothyroidism. Patients diagnosed with asthma were not observed in our study whereas studies from other parts of the world reported chronic asthma patients, ${ }^{5}$ however anti-asthmatics were used by the participants during the first trimester for complains of breathlessness.

Using the USFDA risk classification the percentage of women receiving drugs from different classes were documented. Majority of the drugs used by our study participants were from category B which shows no risk to the foetus in the animal studies. From Table 4, it is observed that category B drugs which included antibiotics such as penicillins, antiemetics, anti-fungals, beta blockers, anti-histamines, cholelithiolytics were the highest, followed by category A which included anti-inflammatory, anti-anaemics, thyroid therapy drugs and anti-diabetics. Few of the participants received category $\mathrm{C}$ drugs which included calcium antagonists, opioid analgesics and vasodilators used for hypertension. Least used drugs belonged to category D which included anti-psychotics which included clonazepam and aminoglycoside antibiotics. Reports on usage of potentially harmful drugs belonging to category $\mathrm{D}$ and $\mathrm{X}$ during pregnancy has also been reported from rural areas in Central India. ${ }^{10}$

The usage of the drugs when classified using the ATC code (Anatomical \& Taxonomical Classification), revealed that the most commonly used class of drugs belonged to anti-infectives (70.4\%) along with anti-emetics followed by anti-diabetics and anti-anaemics which correlates with the USFDA classification data. Anti-infectives being the most commonly prescribed drugs were reported by studies conducted in Germany, ${ }^{14}$ China. ${ }^{5}$

During our study period, observations recorded for 174 participants post partum showed that, majority of the new born babies were normal, however 2 participants were prescribed with category $\mathrm{D}$ and one with category $\mathrm{X}$. These findings are quite similar to studies done elsewhere where women are frequently exposed to drugs with the known risk of which outweigh their benefits. ${ }^{9}$

The major limitation was lack of follow up of the participants from first trimester till post delivery which would be important to study the teratogenic effects of drugs and other limitation was that this was a single centre study.

\section{CONCLUSION}

During pregnancy, women are exposed to at least one or more drugs in spite of the fact that drugs need to be avoided as much as possible. These drugs can include both prescription as well as non-prescription drugs and also dietary supplements like vitamins and minerals.

In our study conducted with 250 participants it was found that drugs were widely prescribed to the participants. An important thing that was observed with the questionnaire administered to the participants was that, most of them had no knowledge about the harmful effects of drugs on the foetus and self-medication was practiced at a higher rate. Here a pharmacist can play a major role in creating awareness about the same. We have classified the drugs prescribed based on both USFDA categorization as well as the Anatomical and Taxonomical Classification. It was observed that majority of the drugs prescribed in our study belonged to the USFDA category $\mathrm{B}$ which are safe to be prescribed during pregnancy and most importantly it was observed that there were no drugs belonging to the category $\mathrm{X}$ which are supposed to be contraindicated during pregnancy. Also the ATC classification showed that the majority of drugs prescribed belonged to the class of anti-infectives followed by anti-diabetics and anti-anaemics. The present study which aimed to examine the pattern of drug use in pregnancy in Bangalore city adds up to the current knowledge which are reported in other parts of India. This collected information can be used to add value to the treatment and use of drugs in maintaining the health of the pregnant women.

\section{REFERENCES}

1. Sharma R, Kapoor, B, Verma, U. Drug utilization pattern during pregnancy in North India. Ind J Med Sci. 2006; 60(7): 277-87. http://dx.doi.org/10.4103/00195359.26602

2. Nielsen GL, Nørgard B, Puho E, Rothman KJ, Sørensen HT, Czeizel AE. Risk of specific congenital abnormalities in offspring of women with diabetes. Diabet Med. 2005 June; 22(6): 693-96. http://dx.doi.org/10.1111/j.14645491.2005.01477.x ; PMid:15910618

3. Punam Sachdeva, B. G. Patel, B. K. Patel. Drug Use in Pregnancy; a Point to Ponder! Indian J Pharm Sci. 2009 Jan-Feb; 71(1):1-7. http://dx.doi.org/10.4103/0250 474X.51941; PMid:20177448 PMCid:PMC2810038

4. Pharmanet.info.com. India: Kulkarni PA, Kasture PV, Maniyar-Drugs in Pregnancy. Cited 2015 Aug 20. Available from: http://www.pharmanet.info.com. 
5. Zhu X, Qi X, Hao J, Huang Z, Zhang Z, Xing X et al. Pattern of Drug Use During the First Trimester among Chinese Women: data from a population based cohort study. Eur J Clin Pharmacol. 2010 May; 66(5):511-18. http://dx.doi. org/10.1007/s00228-009-0781-x PMid:20127231

6. Gharoro EP, Igbafe AA. Pattern of drug use amongst antenatal patients in Benin City, Nigeria. Med Sci Monit. 2000 Jan-Feb; 6(1): 84-87. PMid:11208289

7. UCSF: Clinical an Translational Science Institute. Sample Size Calculators for designing clinical research [cited 2016 Feb 10]. Available from: http://www. sample-size.net/sample-size-conf-interval-mean

8. Hulley SB, Cummings SR, Browner WS, Grady D, NewmanTB. Designing clinical research: an epidemiological approach. $4^{\text {th }}$ ed. Philadelphia, PA: Lippincott Williams and Wilkins; 2013. Appendix 6D, page 80.

9. Lacroix I, Damase-Michel C, Lapeyre-Mestre M, Montastruc JL. Prescription of drugs during pregnancy in France. The Lancet. 2000 Nov; 356(9243): 1735-36. http://dx.doi.org/10.1016/S0140-6736(00)03209-8

10. Anjan Adhikari, Sharmistha Biswas, Raj K. Gupta. Drug utilization pattern in pregnant women in rural areas, India: Cross-sectional observational study.
J Obstet Gynaecol. 2011 Dec; 37(12): 1813-17. http://dx.doi.org/10.1111/j.14470756.2011.01618.x

11. Collaborative group on drug use in pregnancy (C.G.D.U.P.). Medication during pregnancy: an intercontinental cooperative study. Int J Gynaecol Obstet. 1992; 39: 185-196. http://dx.doi.org/10.1016/0020-7292(92)90656-4

12. Malm H, Martikainen J, Klaukka T, Neuvonen PJ. Prescription drugs during and lactation-a Finnish register-based study. Eur J Clin Pharmacol. 2003 Jun; 59(2): 127-33. PMid:12700878

13. Maats FH, Crowther CA. Patterns of vitamin, mineral and herbal supplement use prior to and during pregnancy. Aust N Z J Obstet Gynaecol. 2002 Nov; 42(5): 494-96. http://dx.doi.org/10.1111/j.0004-8666.2002.00494.x ; PMid:12495093

14. Neubert A, Lukas K, Leis T, Dormann H, Brune K, Rascher W. Drug utilisation on a preterm and neonatal intensive care unit in Germany: a prospective, cohort-based analysis. Eur J Clin Pharmacol. 2010 Jan; 66(1):87-95. http:// dx.doi.org/10.1007/s00228-009-0722-8 PMid:19756556

Cite this article : Varghese BM, Vanaja K, Banu R. Assessment of Drug Usage Pattern during Pregnancy at a Tertiary Care Teaching Hospital. J. Med. Public Health, 2016; 6(3):130-5. 